\title{
Prediction of breast cancer sensitivity to neoadjuvant chemotherapy based on status of DNA damage repair proteins
}

\author{
Hideki Asakawa ${ }^{1,2}$, Hirotaka Koizumi ${ }^{3}$, Ayaka Koike ${ }^{1,2}$, Makiko Takahashi $^{3}$, Wenwen Wu', Hirotaka Iwase ${ }^{4}$, \\ Mamoru Fukuda', Tomohiko Ohta ${ }^{1,2^{*}}$
}

\begin{abstract}
Introduction: Various agents used in breast cancer chemotherapy provoke DNA double-strand breaks (DSBs). DSB repair competence determines the sensitivity of cells to these agents whereby aberrations in the repair machinery leads to apoptosis. Proteins required for this pathway can be detected as nuclear foci at sites of DNA damage when the pathway is intact. Here we investigate whether focus formation of repair proteins can predict chemosensitivity of breast cancer.

Methods: Core needle biopsy specimens were obtained from sixty cases of primary breast cancer before and 18-24 hours after the first cycle of neoadjuvant epirubicin plus cyclophosphamide (EC) treatment. Nuclear focus formation of DNA damage repair proteins was immunohistochemically analyzed and compared with tumor response to chemotherapy.
\end{abstract}

Results: EC treatment induced nuclear foci of $\gamma \mathrm{H} 2 \mathrm{AX}$, conjugated ubiquitin, and Rad51 in a substantial amount of cases. In contrast, BRCA1 foci were observed before treatment in the majority of the cases and only decreased after EC in thirteen cases. The presence of BRCA1-, $\gamma \mathrm{H} 2 \mathrm{AX}$-, or Rad51-foci before treatment or the presence of Rad51-foci after treatment was inversely correlated with tumor response to chemotherapy. DNA damage response (DDR) competence was further evaluated by considering all four repair indicators together. A high DDR score significantly correlated with low tumor response to EC and EC + docetaxel whereas other clinicopathological factors analyzed did not.

Conclusions: High performing DDR focus formation resulted in tumor resistance to DNA damage-inducing chemotherapy. Our results suggested an importance of evaluation of DDR competence to predict breast cancer chemosensitivity, and merits further studying into its usefulness in exclusion of non-responder patients.

\section{Introduction}

Recent advances in chemotherapy have significantly improved the prognosis of breast cancer patients. However, prediction of tumor sensitivity to chemotherapy has not reached a high level of confidence, whereas determining sensitivity to hormone therapy or trastuzumab is relatively more established. Estrogen receptor (ER), progesterone receptor (PR) and human epidermal growth factor receptor (HER)2/ErbB2 are practical benchmarks to exclude non-responding patients, and

\footnotetext{
* Correspondence: to@marianna-u.ac.jp

${ }^{1}$ Division of Breast and Endocrine Surgery, Department of Surgery, St. Marianna University School of Medicine, Kawasaki, 216-8511 Japan
}

tailoring treatment based on gene status significantly optimizes the response rate of hormone therapy and trastuzumab, respectively. Prediction of chemosensitivity with equivalent accuracy is currently anticipated to further improve breast cancer prognosis.

Anthracycline-based regimens, such as epirubicin plus cyclophosphamide (EC), and taxanes represent the major chemotherapeutic agents used in the breast cancer field $[1,2]$. Of these, anthracycline-based chemotherapy induces DNA double-strand breaks (DSBs) $[3,4]$, the most cytotoxic DNA lesion, that leads cells into apoptosis especially when relevant repair pathways (represented by homologous recombination (HR) repair) 
are perturbed [5]. It is important to note that DNA damage repair competence varies among individual breast tumors and closely correlates with chemosensitivity. For example, secondary mutations of BRCA1 or BRCA2 (essential factors in the HR pathway) caused by chemotherapy using cisplatin or poly(ADP-ribose) polymerase inhibitor in BRCA1/2-mutated cancers restore the wild-type reading frame and, therefore, the tumor acquires resistance to these drugs [6-8]. These facts indicate that chemosensitivity of BRCA-associated cancers could be strongly affected by DNA damage repair capability. Based on this evidence it has been suggested that HR competence could be a potential biomarker for chemosensitivity [9]. Rad51, a protein that plays a direct role in HR, especially reflects the HR competence of cells. Therefore, knowing its status is likely to be valuable when assessing HR competence in tumor cells in order to instruct therapeutic decisions [9].

The HR pathway for DSB repair is executed by sequential recruitment of repair proteins to chromatin around DNA lesions. Accumulation of the proteins is regulated by complex mechanisms that utilize phosphorylation and ubiquitination modifications mediated by kinases including ataxia telangiectasia mutated (ATM), and at least four ubiquitin E3 ligases, RNF8, RNF168, Rad18, and BRCA1 [10-17]. The Mre11-Rad50-Nbs1 complex first recognizes DSBs and recruits ATM. ATM then phosphorylates the histone variant $\mathrm{H} 2 \mathrm{AX}(\gamma \mathrm{H} 2 \mathrm{AX})$ $[18,19]$ that triggers accumulation of the downstream E3 ligases RNF8 [11-13,20] and RNF168 [14,15]. Lysine 63linked polyubiquitin chains built at the sites of DNA damage by these E3 ligases next recruits the BRCA1Abraxas-RAP80 complex through the RAP80 component, a protein that contains ubiquitin interacting motif domains [21-23]. BRCA1 is then essential in order to recruit repair effector proteins, including Rad51, that perform HR through sister chromatid exchange [24,25]. Depletion of any one of these proteins results in HR deficiency accompanied by loss of Rad51 focus formation, causing cells to become hypersensitive to DSBinducing agents.

In this study we attempt to clarify the value of $\mathrm{HR}$ competence for the prediction of breast cancer chemosensitivity. One contention is that nuclear focus formation of repair proteins in baseline breast cancer tissues is a response to spontaneous DNA damage during cell proliferation and, in turn, may represent a marker of HR competence of cells to exogenous DNA damage. Therefore, it may predict tumor response to DNA damage-inducing chemotherapy such as with EC. Also, the focus formation after chemotherapy could provide us with additional information regarding the DNA damage-response capacity. To verify in vivo whether focus formation of repair proteins actually occurs in response to DNA damage-inducing chemotherapy and whether it correlates with tumor fates after chemotherapy, we analyzed foci in core needle biopsy specimens from breast cancer before and after neoadjuvant EC treatment.

\section{Materials and methods}

\section{Patients and tumors}

Sixty patients with primary breast cancer $(2 \mathrm{~cm}$ or larger) who consecutively underwent neoadjuvant chemotherapy with EC followed by treatment with docetaxel (DOC) at the Division of Breast and Endocrine Surgery, St. Marianna University School of Medicine, Japan, were enrolled in the present study from August 2005 to July 2007. Tumor specimens were obtained by core needle biopsy prior to starting therapy and 18 to 24 hours after the first cycle of EC treatment. Informed consent for the additional core needle biopsy and experimental use of tumor samples was obtained for all patients in accordance with an approved Institutional Review Board application (registration number 946).

The chemotherapy regimen consisted of four 21-day cycles of EC (E: $80 \mathrm{mg} / \mathrm{m}^{2}$ on day 1, C: $600 \mathrm{mg} / \mathrm{m}^{2}$ on day 1 ) followed by four 21-day cycles of DOC (75 mg/ $\mathrm{m}^{2}$ on day 1). $75 \mathrm{mg} / \mathrm{m}^{2}$ DOC was administrated four times as total (only on day 1). There was no increase or decrease of the dose. Tumor size was evaluated by three-dimensional images obtained by helical computed tomography CT scan with a teleradiologic image workstation (ZIOSTATION ${ }^{\oplus}$, Ziosoft Inc., Tokyo, Japan) at baseline, 14 to 21 days after the last cycle of EC, and 21 days after the last cycle of DOC treatment. The effect of chemotherapy on the tumor was assessed as the threedimensional volume reduction rate or tumor response rate. The tumor response was evaluated either by Response Evaluation Criteria in Solid Tumors (RECIST) [26] or by the three-dimensional volume evaluation defined as: complete response (CR; disappearance of the disease), partial response (PR; reduction of tumor volume of $\geq 65 \%$ ), stable disease (SD; volume reduction $<65 \%$ or enlargement $\leq 73 \%$ ), or progressive disease (PD; volume enlargement $\geq 73 \%$ ). These are equivalent to CR (disappearance), PR (reduction of $\geq 30 \%$ ), SD (reduction $<30 \%$ or enlargement $\leq 20 \%$ ), or PD (enlargement $\geq 20 \%$ ) in unidimensional RECIST criteria, respectively (reviewed in [27]). We also analyzed responses with a $50 \%$ border between PR and SD (instead of 65\%) to evaluate more resistant cases.

\section{Immunohistochemical analysis}

Immunohistochemical analysis was performed by the DAKO EnVision system (DAKO, Copenhagen, Denmark) with modifications. Formalin-fixed, paraffinembedded specimens were cut and heated in a water 
bath $\left(95^{\circ} \mathrm{C}, 40\right.$ minutes) in Target Retrieval Solution (pH 9.0, Dako, Carpinteria, CA, USA) for detection of BRCA-1 or in $10 \mathrm{mM}$ sodium citrate buffer ( $\mathrm{pH} 6.0$ ) for $\gamma \mathrm{H} 2 \mathrm{AX}$ and Rad51. No pre-treatment was necessary to detect conjugated ubiquitin. After quenching of endogenous peroxidase, the sections were incubated overnight at $4{ }^{\circ} \mathrm{C}$ with primary antibody at the appropriate dilution [Additional file 1], washed with PBS, and incubated with horseradish peroxidase-labeled polymer conjugated secondary antibody (EnVision+ System, Dako, Carpinteria, CA, USA) for 30 minutes at room temperature. Color development was achieved by 3, 3'-diaminobenzidine tetrahydrochloride. Effectiveness and specificity of each antibody for the detection of DNA damage-induced nuclear foci were verified with cultured cells treated with ionizing radiation (IR) or epirubicin. The immunofluorescent study has been previously described $[28,29]$. The nuclear foci were further analyzed with the protocol used in the tissue stain. The intrinsic subtype[30] was approximated by receptor status determined by standard immunohistochemical and fluorescence in situ hybridization (FISH) analyses: luminal A: ER+ and/or PR+ and HER2-; luminal B: ER+ and/or PR+ and HER2+; HER2: ERand PR- and HER2+; triple negative: ER- and PR- and HER2-. Tumors that were immunochistochemically scored as $3+$, or $2+$ with FISH-positive, were regarded as positive for HER2 status. Cytokeratin (CK) 5/6 expression was also examined to evaluate the basal-like character.

\section{Immunohistochemical scoring}

Taking into consideration that all immunohistochemical markers used in the study localize to sites of DNA damage in the normal HR pathway, we only counted cells displaying nuclear focus formation and disregarded cytoplasmic or diffuse nuclear staining. We scored the nuclear foci staining as follows: $0=$ no positive cells, $1=$ less than $10 \%$ positive cells, $2=10 \%$ or greater, but less than $80 \%$ positive cells, $3=80 \%$ or greater positive cells. Two observers (HA and HK) were blinded to the clinical information to avoid observer subjectivity when evaluating the immunohistochemical staining. To correlate staining with tumor response, we divided the cases into negative and positive samples to simplify the statistical analyses. The positive cases are a total of the categories with a foci score of 1, 2 and 3 . To assess the capacity of the DNA damage response (DDR) using a more comprehensive approach, we configured the DDR score by counting the total number of positive factors present in baseline foci of BRCA1, $\gamma \mathrm{H} 2 \mathrm{AX}$ and Rad51, and EC-induced foci of Rad51, per case.

\section{Statistical analysis}

The variables measured in the study were first investigated for association by the chi-squared contingency table analysis. For rank correlation, Spearman's method was performed to determine the correlation between the foci score of two repair proteins and to determine the correlation between tumor response rate and focus formation of each repair protein or DDR score. For parametric analyses of tumor volume reduction, Student's unpaired t-test and the Tukey-Kramer method were performed for two-factor comparisons and multiple comparisons, respectively. For evaluation of significance of DDR score and other clinicopathological factors in correlation with mean tumor volume reduction or tumor response rate, variant analysis (univariate) or logistic regression analyses (univariate and multivaliate), respectively, were performed. All analyses were carried out using Statview 5 statistical software (SAS Institute Inc, Cary, NC, USA). Statistical significance was declared for $P$ values less than 0.05 .

\section{Results}

\section{Clinical and pathologic features}

Sixty patients with primary breast cancer were included in the present series. All tumors were diagnosed as invasive ductal carcinoma. Patient clinical characteristics are given in Table 1. All triple-negative tumors were positive for CK5/6 (therefore described as basal-like in Table 1) whereas three cases of Luminal A, one case of Luminal B and three cases of HER2 type were positive for CK5/6. Three patients have one first-degree relative with a history of breast cancer and two patients have one second-degree relative with a history of breast or ovarian cancer. All patients completed an EC plus DOC

\section{Table 1 Patient characteristics}

\begin{tabular}{lccc}
\hline $\begin{array}{l}\text { Characteristic } \\
\text { factor }\end{array}$ & $\begin{array}{c}\text { Number of } \\
\text { patients }\end{array}$ & $\begin{array}{l}\text { Characteristic } \\
\text { factor }\end{array}$ & $\begin{array}{c}\text { Number of } \\
\text { patients }\end{array}$ \\
\hline $\begin{array}{l}\text { Age at treatment } \\
\text { start }\end{array}$ & Cancer stage & \\
Median & 50 & I & 0 \\
Range & $34-68$ & II & 53 \\
Lymph node metastasis & & III & 5 \\
Negative & 36 & IV & 2 \\
Positive & 24 & Intrinsic subtype & \\
Tumor stage & & Luminal A & 37 \\
T1 & 0 & Luminal B & 6 \\
T2 & 54 & HER2 & 11 \\
T3 & 6 & Basal-like & 6 \\
T4 & 0 & Total & 60 \\
\hline
\end{tabular}

* intrinsic subtypes were approximated by immunohistochemical receptor status. HER, human epidermal growth factor receptor. 
regimen. Rad51 and $\gamma \mathrm{H} 2 \mathrm{AX}$ stains were not performed on tumor specimens before EC in two patients because of insufficient tumor sample after reserving stocks for clinical use. Tumor size evaluation by CT after treatment with EC plus DOC was not performed for one patient because of the patient's condition. All but one patient received breast surgery after EC and DOC.

\section{Nuclear foci staining of DNA damage repair proteins}

To assess the competence of the DSB repair pathway, we immunohistochemically analyzed $\gamma \mathrm{H} 2 \mathrm{AX}$, conjugated ubiquitin, BRCA1, and Rad51 in nuclear foci based on the idea that these candidates may represent a typical course of the DSB repair cascade [31]. Of these, $\gamma \mathrm{H} 2 \mathrm{AX}$ is the most upstream element, sequentially followed in the cascade by conjugated ubiquitin, BRCA1, and Rad51. Rad51 is the most downstream of these four proteins and is directly involved in HR. However, it should be mentioned that DNA repair failure due to genes at the same level of or downstream of RAD51, such as RAD51AP1 [32] or translesion DNA polymerases $[33,34]$, is an unlikely cause of loss of foci formation of these proteins. In addition to untreated, baseline breast cancer tissues, we analyzed the tissues 18 to 24 hours after the first cycle of EC treatment to obtain further information for the assessment of DNA repair capacity. The antibodies used in this study are commonly used and well characterized in general. In addition we tested background staining and confirmed the specific detection of nuclear foci at DSBs caused by IR or epirubucin treatment (Figure 1).

The immunohistochemical analyzes revealed that in all but two cases, the foci score of at least one of the repair proteins was altered in response to EC treatment. Representative data for immunohistochemical findings of the nuclear focus formation of the repair proteins before and after the first cycle of EC are shown in Figure 2 with panels summarizing the foci scores of the cases. Prior to EC treatment, samples were stained to determine baseline staining of foci. The foci were positive for $\gamma \mathrm{H} 2 \mathrm{AX}$ (20 of 58 cases), BRCA1 (51 of 60 cases), or Rad51 (11 of 58 cases) whereas no cases exhibited foci staining for conjugated ubiquitin ( 0 of 60 cases). In response to EC treatment, the number of foci staining positive for $\gamma \mathrm{H} 2 \mathrm{AX}$ (44 of 58 cases), conjugated ubiquitin (26 of 60 cases), and Rad51 (31 of 58 cases) increased, whereas foci staining for BRCA1 either increased (9 of 60 cases), remained unchanged (38 of 60 cases) or decreased (13 of 60 cases). The reason why BRCA1 foci staining decreased after treatment in some cases is not clear at present but it could be implicated in the presence of BRCA1 foci in normal S-phase that colocalizes with proliferating cell nuclear antigen (PCNA) at DNA replication fork [35]. The foci score of
BRCA1 after EC (EC-induced foci score) significantly correlated with that of $\operatorname{Rad} 51(P=0.0017$; Table 2$)$, likely reflecting the requirement of BRCA1 for Rad51 recruitment at the site of DNA damage. However, no other correlations between repair proteins were observed, and no clear pattern combinations of repair proteins emerged.

\section{Association of focus formation of each repair protein with tumor response to chemotherapy}

To elucidate the possible association between DDR competence and tumor response to chemotherapy, we correlated the presence of individual repair proteins in foci with tumor volume before and after chemotherapy. Tumor volume was measured prior to chemotherapy to establish the baseline volume. The mean volume reduction of tumors after EC and after EC and DOC was 59.7 $\pm 25.8 \%$ and $76.0 \pm 20.7 \%$ of baseline tumor volume, respectively. We analyzed the presence of repair proteins in foci before (baseline foci) and after EC treatment (ECinduced foci), sorted them into positive and negative foci groups for each individual repair protein, and then correlated each group with tumor volume [Additional file 2]. There was a significant difference in tumor volume after EC between BRCA1-positive and BRCA1-negative baseline foci groups $(82.1 \pm 17.8 \%$ vs $55.7 \pm 25.1 \%, P=$ 0.0039 ) [Additional file $2 \mathrm{a}$ ]. We then performed the same analysis after EC and DOC treatment. In addition to BRCA1 $(93.7 \pm 6.6 \%$ vs $72.8 \pm 20.7 \%, P=0.0044)$, significant differences in tumor volume were observed between positive and negative $\gamma \mathrm{H} 2 \mathrm{AX}(78.4 \pm 17.4 \%$ vs $65.6 \pm$ $26.8 \%, P=0.0429)$ and Rad51 baseline foci groups (78.1 $\pm 18.9 \%$ vs $63.6 \pm 24.4 \%, P=0.0351$ ) [Additional file $2 \mathrm{~b}$ ]

We next tested the correlation between scored foci groups and the tumor response rate. The tumor response rate was evaluated with RECIST or threedimensional volume reduction using either $65 \%$ or $50 \%$ of the PR/SD border (as described in the Materials and Methods). Tumor responses to EC and EC plus DOC according to focus formation status are shown in Additional file 3. Contingency table analyses demonstrate significant differences in the EC tumor response rate between BRCA1-positive and BRCA1-negative baseline foci groups and between Rad51-positive and Rad51negative EC-induced foci groups for all three criteria of the response rate (ZIO 65\%, ZIO 50\%, RECIST). There continued to be a significant difference in tumor response rate after $\mathrm{EC}$ and DOC treatment between Rad51-positive and Rad51-negative EC-induced foci groups for all three criteria. In addition, when evaluated with a three-dimensional volume reduction using $50 \%$ of the PR/SD border, significant differences in the tumor response rate to $\mathrm{EC}$ and $\mathrm{DOC}$ were observed between Rad51-positive and Rad51-negative baseline foci groups. 
(a)
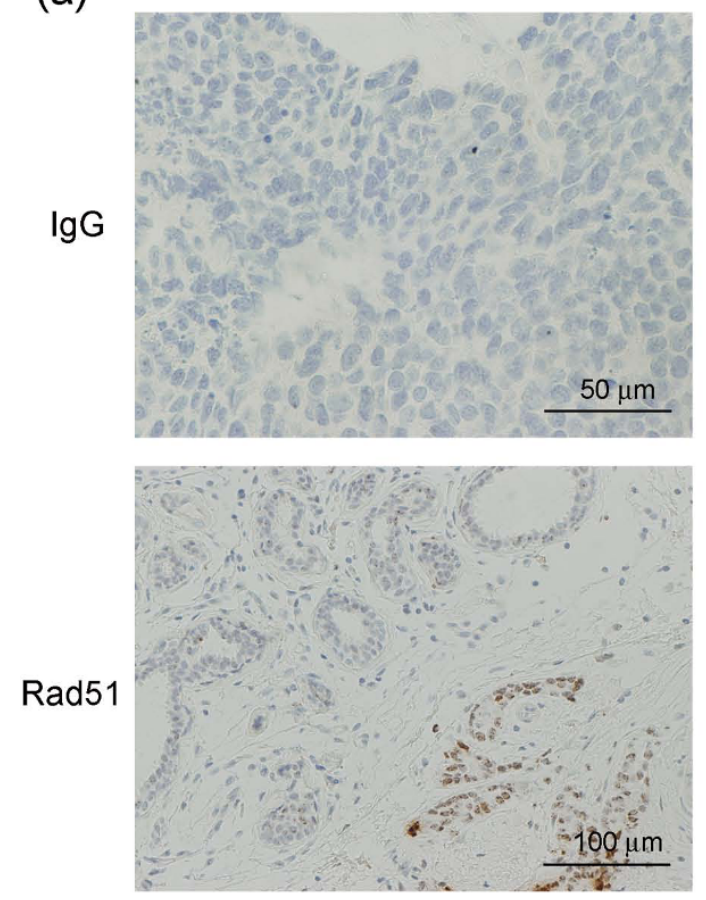

(c)
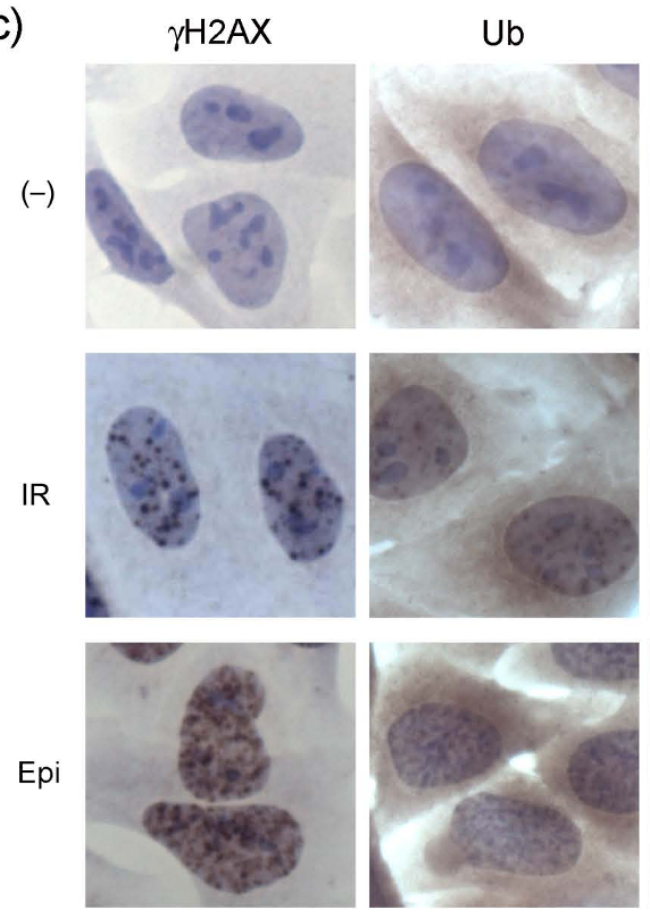

(b)

$(-)$

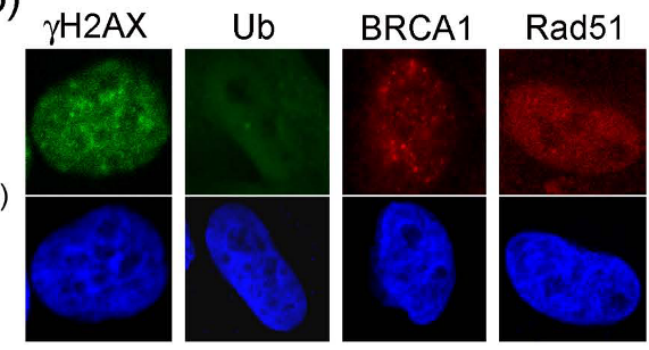

IR
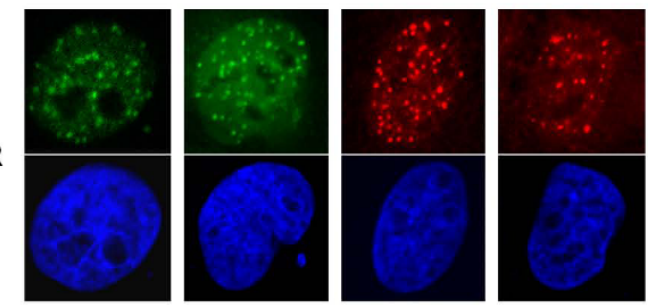

BRCA1

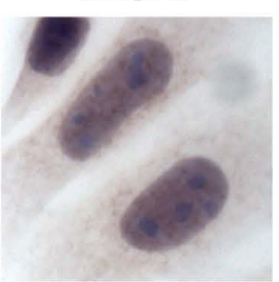

Rad51
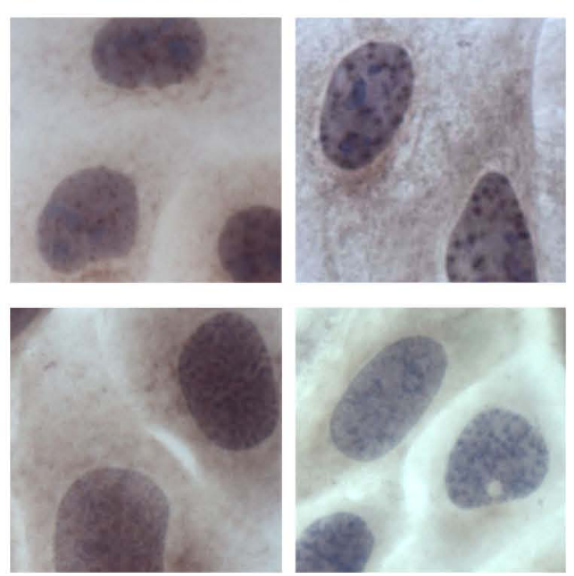

Figure 1 Immunohistochemistry controls and antibody specificity. (a) Immunohistochemical staining with control lgG for tumors after the first cycle of epirubicin plus cyclophosphamide (EC) treatment (upper panel). Lower panel shows Rad51 staining for morphologically diagnosed non-cancerous breast tissues (left upper part) and tumor (right lower part) after the first cycle of EC treatment. Although non-cancerous breast cells also expressed nuclear foci formation the number and intensity was significantly lower than that in tumor cells. (b and c) DNA damageinduced nuclear foci formations detected by antibodies used in the study. HeLa cells were either untreated (-), treated with 5 Gy ionizing radiation (IR) or $0.2 \mu \mathrm{g} / \mathrm{ml}$ epirubicin (Epi), incubated for three hours and fixed. Cells were then subjected either to immunofluorescent analyses with the indicated primary antibodies and (b) FITC- (green) or Rhodamine- (red) conjugated secondary antibodies, or (c) to the same protocol as that used in the tissue stain. For immunofluorescent analyses the nucleus was counterstained with DAPI. Ub, conjugated ubiquitin. 


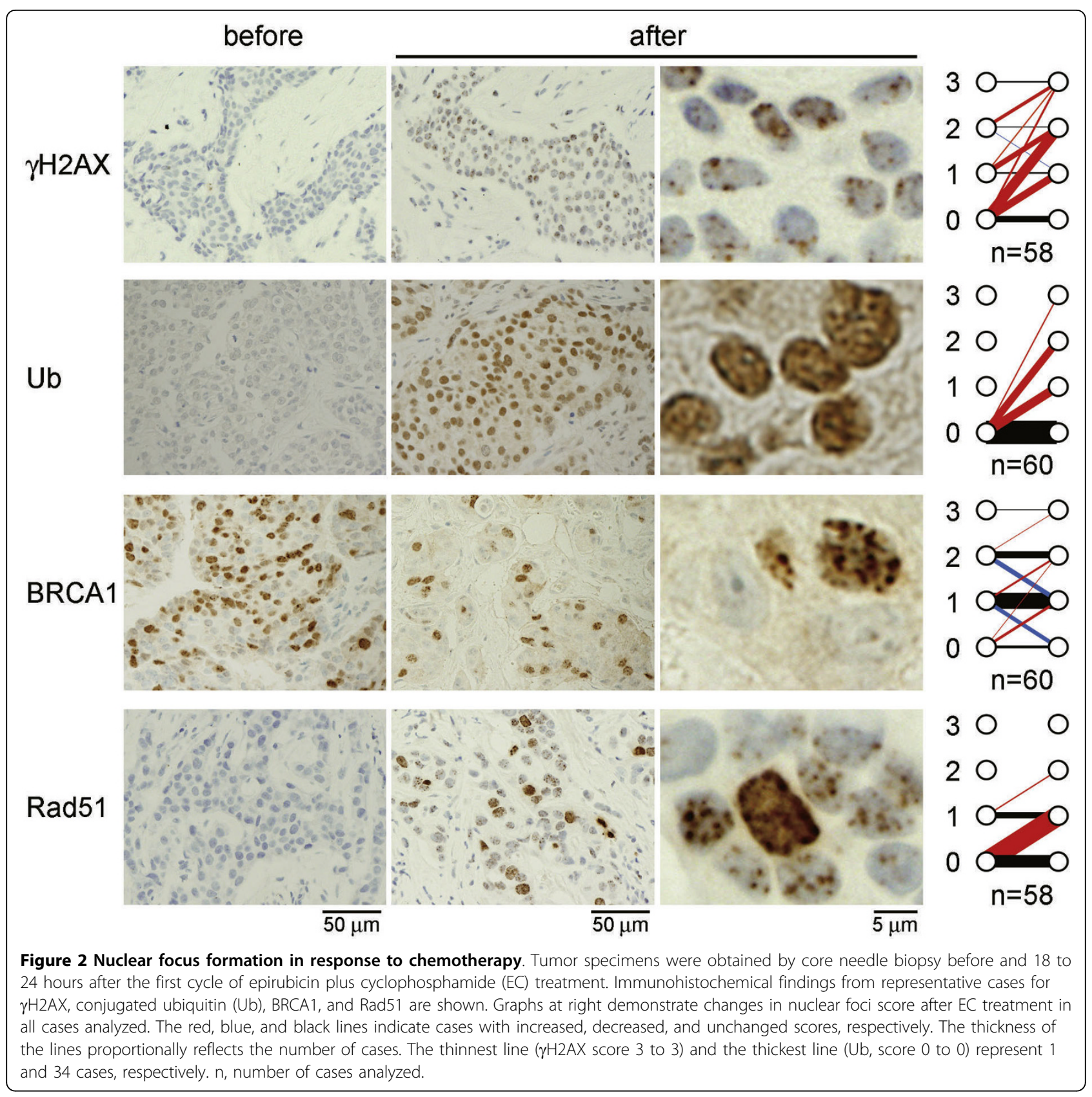

Table 2 Correlation between EC-induced foci of Rad51 and BRCA1

\begin{tabular}{lccccc}
\hline & \multicolumn{5}{c}{ BRCA1 } \\
\cline { 2 - 6 } & $\mathbf{0}$ & $\mathbf{1}$ & $\mathbf{2}$ & $\mathbf{3}$ & Total \\
\hline Rad51 & 7 & 10 & 2 & 0 & 19 \\
0 & 3 & 24 & 9 & 2 & 38 \\
1 & 0 & 0 & 2 & 0 & 2 \\
2 & 10 & 34 & 13 & 2 & 59 \\
Total & & & & & $P=0.0017$
\end{tabular}

$P$ value is from the Spearman's rank correlation test. EC, epirubicin plus cyclophosphamide.
To specify the correlation of these focus formation groups with tumor response rates, we further analyzed the data with Spearman's rank correlation method. When evaluated with three-dimensional volume reduction using $50 \%$ of the PR/SD border, Spearman's analysis showed that the presence of BRCA1-positive baseline foci associated with poor EC tumor response $(P=$ 0.0067) [Additional file 3]. Spearman's analysis also demonstrated that the presence of Rad51-positive baseline foci $(P=0.0078)$ or EC-induced foci $(P=0.0042)$ [Additional file 3] associated with poor EC and DOC tumor response. 


\section{Association of DDR score with tumor reduction by chemotherapy}

The analysis correlating focus formation of BRCA1, $\gamma \mathrm{H} 2 \mathrm{AX}$, and Rad51 prior to treatment and of Rad51 foci after EC treatment with the mean tumor volume reduction or tumor response rate [Additional files 2 and 3] uncovers a significant inverse correlation with tumor response for each of the four conditions. These data support the supposition that higher DDR competency produces tumors resistant to chemotherapy. To correlate overall DDR competency with tumor reduction, we devised a simple measurement to assess DDR competency. Each patient case was analyzed for the presence of all four of the above listed conditions and was assigned a DDR score of 0 to 4 based on the number of conditions present. This DDR score was then correlated with mean tumor volume reductions. Number of cases in each DDR score is shown in Table 3. As shown in Figure 3, both the mean tumor volume reductions after EC $(28.4 \pm 28.1 \%)$ and after EC and DOC (49.9 $\pm 22.0 \%)$ for DDR score 4 (all four conditions present) were the lowest among all the scores. There were significant differences between score 4 and either score 0 or 2 for the mean tumor volume reductions after EC (Figure 3a) and between score 4 and either score 0,1 or 2 for the mean tumor volume reductions after EC and DOC (Figure 3b), as judged by the TukeyKramer multiple comparisons study setting $P<0.05$ as a significance threshold. In addition, Spearman's analysis showed that a high DDR score was associated with poor tumor response rate after EC and DOC $(P=0.0031)$ when evaluated with three-dimensional volume reduction using $50 \%$ of the PR/SD border (Table 3 ). A high DDR score also tended to be associated with poor tumor response rate after $\mathrm{EC}(P=0.0639$, Table 3$)$.

Table 3 Correlation between DDR score and tumor response rate (ZIO 50\%)

\begin{tabular}{lcccccc}
\hline & \multicolumn{6}{c}{ DDR score } \\
\cline { 2 - 7 } & $\mathbf{0}$ & $\mathbf{1}$ & $\mathbf{2}$ & $\mathbf{3}$ & $\mathbf{4}$ & Total \\
\hline After EC & 1 & 0 & 1 & 0 & 0 & 2 \\
CR & 1 & 12 & 14 & 9 & 2 & 38 \\
PR & 0 & 3 & 8 & 3 & 4 & 18 \\
SD & 2 & 15 & 23 & 12 & 6 & 58 \\
Total & & & & & & $P=0.0639$ \\
& 1 & 1 & 3 & 1 & 0 & 6 \\
After EC + DOC & 1 & 13 & 19 & 9 & 2 & 44 \\
CR & 0 & 0 & 1 & 2 & 4 & 7 \\
PR & 2 & 14 & 23 & 12 & 6 & 57 \\
SD & & & & & & $P=0.0031$ \\
Total & & & & & & \\
& & & & & &
\end{tabular}

$P$ values are from the Spearman's rank correlation test. $C R$, complete response; DDR, DNA damage response; EC, epirubicin plus cyclophosphamide; PR, partial response; $\mathrm{SD}$, stable disease.

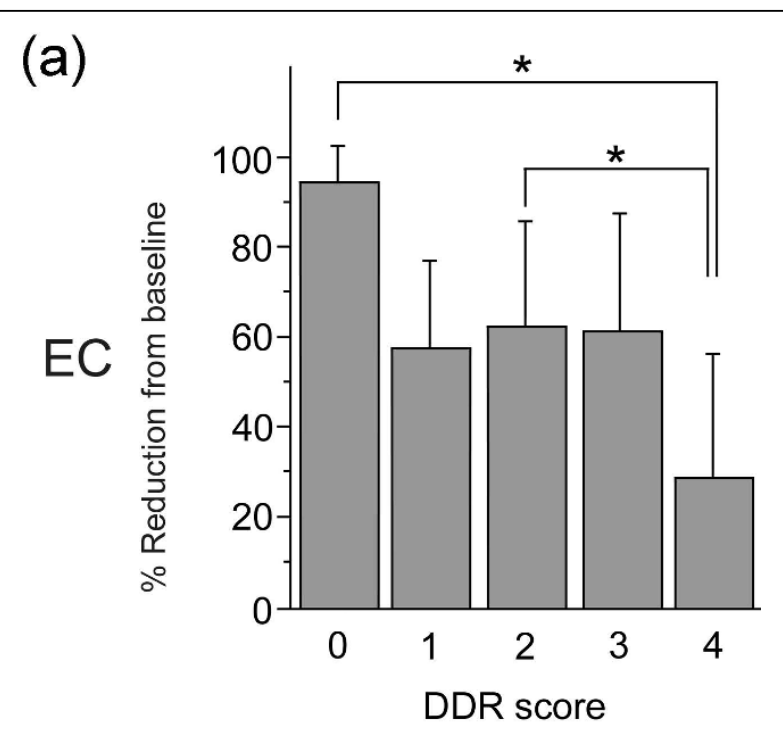

(b)

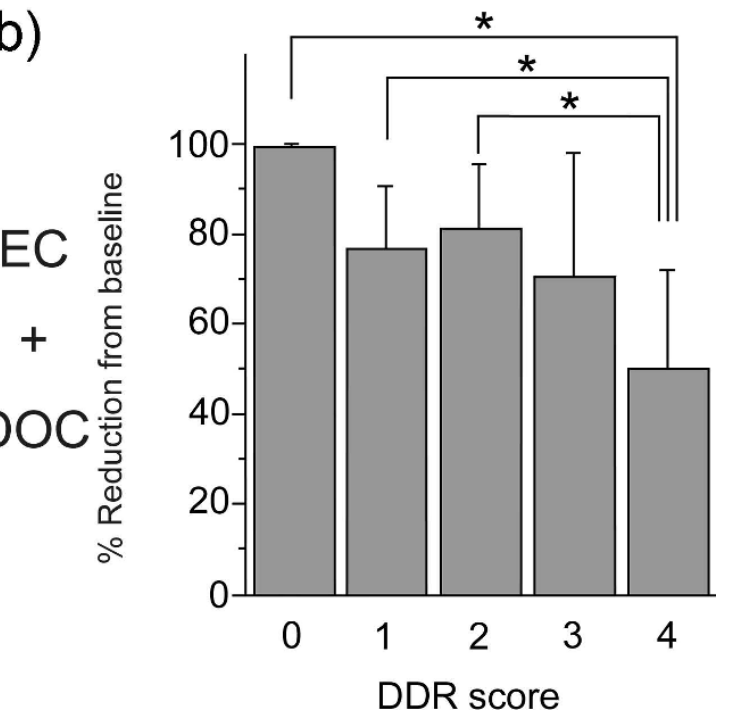

Figure 3 Mean tumor volume reductions after (a) EC or (b) EC and DOC according to DDR score. Error bars represent standard deviation. Significance was analyzed by Tukey-Kramer test setting $P$ $<0.05$ as significance threshold. DDR, DNA damage response; DOC, docetaxel; EC, epirubicin plus cyclophosphamide.

The correlation between DDR score and the tumor response prompted us to examine whether it has a significant impact among other clinicopathological factors including age, cancer stage, tumor size, nodal metastatic status, and subtypes. None of these factors correlated with DDR score (data not shown). The variant analysis for mean tumor volume reduction after $\mathrm{EC}$ revealed that only DDR score $(P=0.0069)$, but no other factors correlated with the mean tumor volume reduction (Table 4). The variant analysis for mean tumor volume reduction after EC and DOC also demonstrated DDR 
score $(P=0.0035)$ as the most significant correlation factor, followed by nodal status $(P=0.0201)$ and tumor size $(P=0.0538$, Table 4$)$. In addition, univariate logistic regression analysis showed that a high (3 and 4) DDR score was most significantly associated with poor tumor response after EC and DOC $(P=0.0095)$ when evaluated with volume reduction using $50 \%$ of the PR/SD border, followed by tumor size $(P=0.0260)$, cancer stage $(P=0.0465)$, and subtype $(P=0.0659$, Table 5$)$. We then examined multivariate analysis with tumor size, nodal status, subtype, and DDR score, the factors that showed probable association with tumor response rate in the univariate analysis. Cancer stage was omitted because it was correlated with tumor size. Importantly the result indicated that only the DDR score was significantly associated with tumor response rate $(P=0.0402)$ independent of other factors analyzed (Table 6).

\section{Discussion}

In the present study using human tumor specimens we show for the first time that DNA repair competence may predict breast cancer sensitivity to DNA damage-inducing chemotherapy. We selected $\gamma \mathrm{H} 2 \mathrm{AX}$, conjugated ubiquitin, BRCA1, and Rad51, proteins in the DSB repair cascade, to assess DNA repair competence because accumulated evidence demonstrates that inactivation of genes in the DSB repair pathway results in cellular sensitivity to DNA damage-inducing chemotherapy $[16,29,31,36-38]$. In our study, these repair proteins dramatically responded to EC treatment. The conjugated ubiquitin response was especially dramatic as approximately half of the cases analyzed formed conjugated ubiquitin foci, compared with undetectable foci formation prior to treatment. This suggests that ubiquitination occurs in vivo during the DNA damage response in an early stage after chemotherapy. However, in spite of the dramatic response, we did not find any significant correlation between conjugated ubiquitin foci formation and tumor response. The reason is currently unknown. One possibility is that this could be attributed to the fact that ubiquitination is also involved in DNA damage response pathways other than for DSBs.

We did not find certain trends of the combinations of responding repair proteins. Several reasons could account for this observation. First, the metabolism and pharmacokinetics of the agents could vary per patient. The ideal time to obtain the in vivo sample was, therefore, difficult to determine. The experimental design employed in this study was not very robust in this way. In cultured cells, $\gamma \mathrm{H} 2 \mathrm{AX}$ accumulates at sites of DNA damage just minutes after the damage occurs, whereas BRCA1 and Rad51 foci appear 30 minutes to several hours afterwards $[11,35,39,40]$. In this study we harvested samples 18 to 24 hours after EC treatment because the agents were still expected to be present in patients and we also considered the patient's convenience. However, the ideal timing remains to be determined if biopsy after chemotherapy is required.

The second reason for the diversity of the DDR response could be attributed to the diversity of aberrations of the genes responsible for DSB repair in each breast cancer. Theoretically, defects in the recruitment of upstream repair proteins could result in loss of downstream proteins at sites of DNA damage, and this has been shown to be the case in many molecular biological studies using cultured cells [10-15,21-23]. Furthermore, it was also shown that Rad51 nuclear expression is absent in tumors associated with BRCA2 mutation [41]. The positive correlation found between EC-induced BRCA1 and Rad51 foci in this study (Table 2) may also support this interpretation. In contrast, it was reported that overexpression of Rad51 restored Rad51 focus formation and rescued the sensitivity of BRCA1-deficient cells to $\mathrm{x}$-rays and cisplatin [42]. Importantly, up-regulation of Rad51 was a common feature of BRCA1-deficient breast tumors [42]. These data suggest that the mechanism of DSB repair response in vivo is not simple and that assessment of DSB repair aberrations in each patient case is, therefore, unreasonable at present.

In an attempt to address this problem in our current study, we assessed the comprehensive capacity of DSB repair by incorporating multiple candidate factors into one DDR score. We found that foci of BRCA1, $\gamma \mathrm{H} 2 \mathrm{AX}$, and Rad51 prior to treatment and EC-induced foci of Rad51 correlated with tumor response when compared either with the mean tumor volume reduction or the tumor response rate. When incorporating these four factors into one DDR score a significant correlation was observed with mean tumor volume reduction after EC, whereas no other factors correlated with the mean tumor volume reduction (Table 4 and Figure 3a). Although it was not statistically significant, the similar correlation was also observed between DDR score and tumor response rate (Table 3). These correlations became more significant after EC and DOC treatment (Tables 3 to 5 and Figure $3 \mathrm{~b}$ ) and the DDR score was an independent predictive factor of other factors including tumor subtype when evaluated with volume reduction using $50 \%$ of the PR/SD border (Table 6). Recent studies suggested that luminal tumors have low response rate to neoadjuvant chemotherapy, whereas basal-like and HER2+ tumors have higher response rates. For example, it has been reported that clinical response rate (CR and PR) to anthracyclin-based chemotherapy of luminal A was $39 \%$, whereas that of basal-like, which has been implicated with BRCA1 dysfunction $[43,44]$, was $85 \%$ [45]. The response rates to EC treatment of luminal A (15 of 37 cases, 40.5\%) and basal-like (4 of 6 cases, $66.7 \%$ ) subtypes in the current study were not 
Table 4 Univariate analysis of variance for mean tumor volume reduction

\begin{tabular}{|c|c|c|c|}
\hline & $n$ & $\begin{array}{l}\text { Mean tumor volume } \\
\text { reduction }(\%) \pm S D\end{array}$ & $P$ \\
\hline \multicolumn{4}{|l|}{ After EC } \\
\hline \multicolumn{4}{|l|}{ Age (years) } \\
\hline-50 & 30 & $64.1 \pm 25.9$ & 0.1710 \\
\hline $51-$ & 29 & $54.9 \pm 25.4$ & \\
\hline \multicolumn{4}{|l|}{ Cancer stage } \\
\hline$\|$ & 53 & $61.5 \pm 25.1$ & 0.0962 \\
\hline III & 5 & $55.7 \pm 29.1$ & \\
\hline IV & 2 & $21.9 \pm 6.4$ & \\
\hline \multicolumn{4}{|l|}{ Tumor stage } \\
\hline $\mathrm{T} 2$ & 54 & $60.8 \pm 25.3$ & 0.3059 \\
\hline T3 & 6 & $21.9 \pm 6.4$ & \\
\hline \multicolumn{4}{|l|}{ Nodal status } \\
\hline N- & 24 & $62.7 \pm 24.9$ & 0.4557 \\
\hline $\mathrm{N}+$ & 36 & $57.6 \pm 26.6$ & \\
\hline \multicolumn{4}{|l|}{ Subtype } \\
\hline Luminal A & 37 & $58.8 \pm 21.3$ & 0.2923 \\
\hline Luminal B & 6 & $72.9 \pm 9.4$ & \\
\hline HER2 & 11 & $50.4 \pm 36.4$ & \\
\hline Basal-like & 6 & $69.4 \pm 37.0$ & \\
\hline \multicolumn{4}{|l|}{ DDR score } \\
\hline 0 & 2 & $94.6 \pm 7.6$ & 0.0069 \\
\hline 1 & 15 & $57.3 \pm 19.4$ & \\
\hline 2 & 23 & $62.8 \pm 22.9$ & \\
\hline 3 & 12 & $61.1 \pm 26.6$ & \\
\hline 4 & 6 & $28.4 \pm 28.1$ & \\
\hline \multicolumn{4}{|l|}{ After EC-DOC } \\
\hline \multicolumn{4}{|l|}{ Age } \\
\hline-50 & 30 & $80.6 \pm 23.9$ & 0.0804 \\
\hline $51-$ & 29 & $71.2 \pm 15.7$ & \\
\hline \multicolumn{4}{|l|}{ Cancer stage } \\
\hline$\|$ & 52 & $77.9 \pm 19.8$ & 0.1230 \\
\hline III & 5 & $64.3 \pm 25.7$ & \\
\hline IV & 2 & $54.7 \pm 17.6$ & \\
\hline \multicolumn{4}{|l|}{ Tumor stage } \\
\hline $\mathrm{T} 2$ & 53 & $77.7 \pm 19.7$ & 0.0538 \\
\hline $\mathrm{T} 3$ & 6 & $60.6 \pm 24.7$ & \\
\hline \multicolumn{4}{|l|}{ Nodal status } \\
\hline N- & 23 & $83.7 \pm 14.3$ & 0.0201 \\
\hline $\mathrm{N}+$ & 36 & $71.0 \pm 22.7$ & \\
\hline \multicolumn{4}{|l|}{ Subtype } \\
\hline Luminal A & 36 & $77.9 \pm 16.1$ & 0.0789 \\
\hline Luminal B & 6 & $86.0 \pm 9.5$ & \\
\hline HER2 & 11 & $62.4 \pm 30.5$ & \\
\hline Basal-like & 6 & $79.7 \pm 24.8$ & \\
\hline \multicolumn{4}{|l|}{ DDR score } \\
\hline 0 & 2 & $99.6 \pm 0.6$ & 0.0035 \\
\hline 1 & 14 & $77.2 \pm 13.2$ & \\
\hline 2 & 23 & $81.0 \pm 14.7$ & \\
\hline
\end{tabular}

Table 4: Univariate analysis of variance for mean tumor volume reduction (Continued)

\begin{tabular}{ccc}
\hline 3 & 12 & $70.7 \pm 27.5$ \\
4 & 6 & $49.9 \pm 22.0$ \\
\hline
\end{tabular}

DDR, DNA Damage Response; DOC, docetaxel; EC, epirubicin plus cyclophosphamide; HER, human epidermal growth factor receptor; SD, standard deviation.

Table 5 Univariate logistic regression analysis of factors affecting tumor response rate (ZIO 50\%)

\begin{tabular}{cccc}
\hline & Odds ratio & $(\mathbf{9 5 \%}$ Cl) & $\boldsymbol{P}$ \\
\hline $\begin{array}{c}\text { After EC + DOC } \\
\text { Age (years) }\end{array}$ & & & \\
$<51$ & 1.000 & & \\
$51 \leq$ & 0.800 & $(0.192-3.333)$ & 0.7592 \\
Cancer stage & & & \\
II & 1.000 & & \\
III, IV & 5.750 & $(1.028-32.174)$ & 0.0465 \\
Tumor stage & & & \\
T2 & 1.000 & & \\
T3 & 7.833 & $(1.279-47.964)$ & 0.0260 \\
Nodal status & & & \\
N- & 1.000 & & \\
N+ & 6.286 & $(0.730-54.110)$ & 0.0942 \\
Subtype & & & \\
Luminal A, B & 1.000 & & 0.0659 \\
HER2, Basal-like & 3.958 & $(0.913-17.154)$ & \\
DDR score & & & \\
0, 1, 2 & 1.000 & & \\
3, 4 & 9.423 & $(1.729-51.359)$ & 0.0095 \\
\hline
\end{tabular}

$\mathrm{Cl}$, confidence interval; DDR, DNA Damage Response; DOC, docetaxel; EC, epirubicin plus cyclophosphamide; HER, human epidermal growth factor receptor.

very different from the previous report. However, we could not find any correlation between subtype and DDR score while DDR score independently predicted the chemosensitivity. The result may reflect the fact that luminal A tumors also include DNA damage-sensitive tumors with defective HR pathways that can be counted by the DDR score. Supporting this it has been shown that tumors caused by BRCA 2 deficiency mainly become luminal A tumors $[44,46,47]$.

The reason why the correlation between the DDR score and tumor response after EC and DOC treatment became more significant than that after EC is not clear at present. As DOC does not induce DNA DSBs, the observed effect is not likely to be due to the sensitivity to DNA damage in those tumors. DOC might be more toxic for the cells with gross genomic aberration caused by the pretreatment with EC under the condition of being less HR competent. Alternatively it is possible that time length after EC treatment enhanced the difference of the outcome. 
Table 6 Multivariate logistic regression analysis of factors affecting tumor response rate (ZIO 50\%)

\begin{tabular}{cccc}
\hline & Odds ratio & $\mathbf{( 9 5 \% ~ C l )}$ & $\boldsymbol{P}$ \\
\hline $\begin{array}{c}\text { After EC + DOC } \\
\text { Tumor stage } \\
\text { T2 }\end{array}$ & & & \\
T3 & 1.000 & & \\
Nodal status & 2.246 & $(0.290-17.420)$ & 0.4388 \\
N- & & & \\
N+ & 1.000 & & \\
Subtype & 3.651 & $(0.346-38.506)$ & 0.2813 \\
Luminal A, B & 1.000 & & \\
HER2, Basal-like & 2.484 & $(0.464-13.287)$ & 0.2874 \\
DDR score & & & \\
0, 1, 2 & 1.000 & & \\
3, 4 & 6.694 & $(1.088-41.182)$ & 0.0402 \\
\hline
\end{tabular}

$\mathrm{Cl}$, confidence interval; DDR, DNA Damage Response; DOC, docetaxel; EC, epirubicin plus cyclophosphamide; HER, human epidermal growth factor receptor.

Interestingly, DDR score group 4 consisted of cases with poor tumor responses to chemotherapy when evaluated for both mean tumor volume reduction (Figure 3) and tumor response rate (Table 3). This result may lead to the possibility of using DDR status in the clinic to predict and exclude non-responders to EC treatment. It is noteworthy to point out that the HR repair cascade for DSB contains many essential proteins other than those tested in this study. By including select subsets of proteins for analysis, it may be possible to identify nonresponders in order to avoid unnecessary chemotherapy. Ideally in such cases, the levels of baseline foci present prior to treatment would provide enough information to determine appropriate treatment, preventing the need for additional core needle biopsy after chemotherapy.

\section{Conclusions}

In conclusion, our results suggest the importance of evaluating DDR competence to predict breast cancer chemosensitivity and warrant further investigation into its effectiveness as a way to exclude non-responding patients.

Additional file 1: Table S1. Antibodies used in the present

immunohistochemical study.

Additional file 2: Figure S1. Mean tumor volume reduction after EC (a) or EC+DOC (b) according to the nuclear foci status for DNA repair proteins.

Additional file 3: Table S2. Tumor response rate according to the nuclear foci status for DNA repair proteins.

\section{Abbreviations}

CK: cytokeratin; CR: complete response; CT: computed tomography; DDR: DNA damage response; DOC: docetaxel; DSB: DNA double-strand break; EC: epirubicin plus cyclophosphamide; ER: estrogen receptor; HER: human epidermal growth factor receptor; HR: homologous recombination repair; IR: ionizing radiation; PBS: phosphate-buffered saline; PD: progressive disease; PR: partial response; PR (+ or -): progesterone receptor (+ or -); RECIST: Response Evaluation Criteria in Solid Tumors; SD: stable disease.

\section{Acknowledgements}

This study was supported by grants from the Ministry of Education, Science, Sports, Culture and Technology of Japan grants-in-aid. We thank Mrs. Shigeko Ohnuma for technical support for immunohistochemical experiments; Dr. Yasuo Miyoshi for technical advice; Dr. Ettore Appella for critical reading of the manuscript; Members in the Division of Breast and Endocrine Surgery for support in collection of biopsy specimens; and Mrs. Rie Ogawa and Miss Umi Noguchi for secretarial assistance.

\section{Author details}

${ }^{1}$ Division of Breast and Endocrine Surgery, Department of Surgery, St. Marianna University School of Medicine, Kawasaki, 216-8511 Japan. ${ }^{2}$ Department of Translational Oncology, St. Marianna University Graduate School of Medicine, Kawasaki, 216-8511 Japan. ${ }^{3}$ Department of Diagnostic Pathology, St. Marianna University School of Medicine, Kawasaki, 216-8511 Japan. ${ }^{4}$ Department of Breast and Endocrine Surgery, Kumamoto University, Honjo 1-1-1, Kumamoto 860-8556, Japan.

\section{Authors' contributions}

HA analyzed the majority of the data. HK conducted immunohistochemical analyses. AK obtained the data for tumor response. MT supported immunohistochemical analyses. WW characterized antibody specificities. HI and MF made substantial contributions to analysis and interpretation of the data. TO designed and conducted the studies, and wrote the manuscript. All authors read and approved the final manuscript.

\section{Competing interests}

The authors declare that they have no competing interests.

Received: 18 September 2009 Revised: 7 January 2010

Accepted: 5 March 2010 Published: 5 March 2010

\section{References}

1. Trudeau M, Charbonneau F, Gelmon K, Laing K, Latreille J, Mackey J, McLeod D, Pritchard K, Provencher L, Verma S: Selection of adjuvant chemotherapy for treatment of node-positive breast cancer. Lancet Oncol 2005, 6:886-898.

2. Effects of chemotherapy and hormonal therapy for early breast cancer on recurrence and 15-year survival: an overview of the randomised trials. Lancet 2005, 365:1687-1717.

3. Capranico G, Zunino F, Kohn KW, Pommier Y: Sequence-selective topoisomerase II inhibition by anthracycline derivatives in SV40 DNA: relationship with DNA binding affinity and cytotoxicity. Biochemistry 1990, 29:562-569.

4. Capranico G, De Isabella P, Penco S, Tinelli S, Zunino F: Role of DNA breakage in cytotoxicity of doxorubicin, 9-deoxydoxorubicin, and 4-demethyl-6-deoxydoxorubicin in murine leukemia P388 cells. Cancer Res 1989, 49:2022-2027.

5. Sancar A, Lindsey-Boltz LA, Unsal-Kacmaz K, Linn S: Molecular mechanisms of mammalian DNA repair and the DNA damage checkpoints. Annu Rev Biochem 2004, 73:39-85.

6. Sakai W, Swisher EM, Karlan BY, Agarwal MK, Higgins J, Friedman C, Villegas E, Jacquemont C, Farrugia DJ, Couch FJ, Urban N, Taniguchi T: Secondary mutations as a mechanism of cisplatin resistance in BRCA2mutated cancers. Nature 2008, 451:1116-1120.

7. Edwards SL, Brough R, Lord CJ, Natrajan R, Vatcheva R, Levine DA, Boyd J, Reis-Filho JS, Ashworth A: Resistance to therapy caused by intragenic deletion in BRCA2. Nature 2008, 451:1111-1115.

8. Swisher EM, Sakai W, Karlan BY, Wurz K, Urban N, Taniguchi T: Secondary BRCA1 mutations in BRCA1-mutated ovarian carcinomas with platinum resistance. Cancer Res 2008, 68:2581-2586.

9. Livingston DM, Silver DP: Cancer: crossing over to drug resistance. Nature 2008, 451:1066-1067. 
10. Wang B, Elledge SJ: Ubc13/Rnf8 ubiquitin ligases control foci formation of the Rap80/Abraxas/Brca1/Brcc36 complex in response to DNA damage. Proc Natl Acad Sci USA 2007, 104:20759-20763.

11. Mailand N, Bekker-Jensen S, Faustrup H, Melander F, Bartek J, Lukas C, Lukas J: RNF8 Ubiquitylates Histones at DNA Double-Strand Breaks and Promotes Assembly of Repair Proteins. Cell 2007, 131:887-900.

12. Kolas NK, Chapman JR, Nakada S, Ylanko J, Chahwan R, Sweeney FD, Panier S, Mendez M, Wildenhain J, Thomson TM, Pelletier L, Jackson SP, Durocher D: Orchestration of the DNA-damage response by the RNF8 ubiquitin ligase. Science 2007, 318:1637-1640.

13. Huen MS, Grant R, Manke I, Minn K, Yu X, Yaffe MB, Chen J: RNF8 Transduces the DNA-Damage Signal via Histone Ubiquitylation and Checkpoint Protein Assembly. Cell 2007, 131:901-914.

14. Doil C, Mailand N, Bekker-Jensen S, Menard P, Larsen DH, Pepperkok R, Ellenberg J, Panier S, Durocher D, Bartek J, Lukas J, Lukas C: RNF168 binds and amplifies ubiquitin conjugates on damaged chromosomes to allow accumulation of repair proteins. Cell 2009, 136:435-446.

15. Stewart GS, Panier S, Townsend K, Al-Hakim AK, Kolas NK, Miller ES, Nakada S, Ylanko J, Olivarius S, Mendez M, Oldreive C, Wildenhain J, Tagliaferro A, Pelletier L, Taubenheim N, Durandy A, Byrd PJ, Stankovic T, Taylor AM, Durocher D: The RIDDLE syndrome protein mediates a ubiquitin-dependent signaling cascade at sites of DNA damage. Cell 2009, 136:420-434

16. Wu W, Koike A, Takeshita T, Ohta T: The ubiquitin E3 ligase activity of BRCA1 and its biological functions. Cell Div 2008, 3:1.

17. Huang J, Huen MS, Kim H, Leung CC, Glover JN, Yu X, Chen J: RAD18 transmits DNA damage signalling to elicit homologous recombination repair. Nat Cell Biol 2009, 11:592-603.

18. Bassing $\mathrm{CH}$, Suh $\mathrm{H}$, Ferguson DO, Chua KF, Manis J, Eckersdorff $M$, Gleason M, Bronson R, Lee C, Alt FW: Histone H2AX: a dosage-dependent suppressor of oncogenic translocations and tumors. Cell 2003, 114:359-370.

19. Celeste A, Fernandez-Capetillo O, Kruhlak MJ, Pilch DR, Staudt DW, Lee A, Bonner RF, Bonner WM, Nussenzweig A: Histone H2AX phosphorylation is dispensable for the initial recognition of DNA breaks. Nat Cell Biol 2003, 5:675-679.

20. Plans V, Scheper J, Soler M, Loukili N, Okano Y, Thomson TM: The RING finger protein RNF8 recruits UBC13 for lysine 63-based self polyubiquitylation. J Cell Biochem 2006, 97:572-582.

21. Kim H, Chen J, Yu X: Ubiquitin-binding protein RAP80 mediates BRCA1dependent DNA damage response. Science 2007, 316:1202-1205.

22. Sobhian B, Shao G, Lilli DR, Culhane AC, Moreau LA, Xia B, Livingston DM, Greenberg RA: RAP80 targets BRCA1 to specific ubiquitin structures at DNA damage sites. Science 2007, 316:1198-1202.

23. Wang B, Matsuoka S, Ballif BA, Zhang D, Smogorzewska A, Gygi SP, Elledge SJ: Abraxas and RAP80 form a BRCA1 protein complex required for the DNA damage response. Science 2007, 316:1194-1198.

24. Greenberg RA, Sobhian B, Pathania S, Cantor SB, Nakatani Y, Livingston DM: Multifactorial contributions to an acute DNA damage response by BRCA1/BARD1-containing complexes. Genes Dev 2006, 20:34-46.

25. Yu DS, Sonoda E, Takeda S, Huang CL, Pellegrini L, Blundell TL, Venkitaraman AR: Dynamic control of Rad51 recombinase by selfassociation and interaction with BRCA2. Mol Cell 2003, 12:1029-1041.

26. Therasse P, Arbuck SG, Eisenhauer EA, Wanders J, Kaplan RS, Rubinstein L, Verweij J, Van Glabbeke M, van Oosterom AT, Christian MC, Gwyther SG: New guidelines to evaluate the response to treatment in solid tumors. European Organization for Research and Treatment of Cancer, National Cancer Institute of the United States, National Cancer Institute of Canada. J Natl Cancer Inst 2000, 92:205-216.

27. Jaffe CC: Measures of response: RECIST, WHO, and new alternatives. $J$ Clin Oncol 2006, 24:3245-3251.

28. Sato K, Hayami R, Wu W, Nishikawa T, Nishikawa H, Okuda Y, Ogata $H$, Fukuda M, Ohta T: Nucleophosmin/B23 is a candidate substrate for the BRCA1-BARD1 ubiquitin ligase. J Biol Chem 2004, 279:30919-30922.

29. Takeshita T, Wu W, Koike A, Fukuda M, Ohta T: Perturbation of DNA repair pathways by proteasome inhibitors corresponds to enhanced chemosensitivity of cells to DNA damage-inducing agents. Cancer Chemother Pharmacol 2009, 64:1039-46.

30. Sorlie T, Perou CM, Tibshirani R, Aas T, Geisler S, Johnsen H, Hastie T, Eisen MB, Rijn van de M, Jeffrey SS, Thorsen T, Quist H, Matese JC, Brown PO, Botstein D, Eystein Lonning P, Borresen-Dale AL: Gene expression patterns of breast carcinomas distinguish tumor subclasses with clinical implications. Proc Natl Acad Sci USA 2001, 98:10869-10874.

31. Harper JW, Elledge SJ: The DNA damage response: ten years after. Mol Cell 2007, 28:739-745.

32. Wiese C, Dray E, Groesser T, San Filippo J, Shi I, Collins DW, Tsai MS, Williams GJ, Rydberg B, Sung P, Schild D: Promotion of homologous recombination and genomic stability by RAD51AP1 via RAD51 recombinase enhancement. Mol Cell 2007, 28:482-490.

33. Kawamoto T, Araki K, Sonoda E, Yamashita YM, Harada K, Kikuchi K, Masutani C, Hanaoka F, Nozaki K, Hashimoto N, Takeda S: Dual roles for DNA polymerase eta in homologous DNA recombination and translesion DNA synthesis. Mol Cell 2005, 20:793-799.

34. Mcllwraith MJ, Vaisman A, Liu Y, Fanning E, Woodgate R, West SC: Human DNA polymerase eta promotes DNA synthesis from strand invasion intermediates of homologous recombination. Mol Cell 2005, 20:783-792.

35. Scully R, Chen J, Ochs RL, Keegan K, Hoekstra M, Feunteun J, Livingston DM: Dynamic changes of BRCA1 subnuclear location and phosphorylation state are initiated by DNA damage. Cell 1997, 90:425-435.

36. Murakawa Y, Sonoda E, Barber LJ, Zeng W, Yokomori K, Kimura H, Niimi A, Lehmann A, Zhao GY, Hochegger H, Boulton SJ, Takeda S: Inhibitors of the proteasome suppress homologous DNA recombination in mammalian cells. Cancer Res 2007, 67:8536-8543.

37. Collis SJ, Swartz MJ, Nelson WG, DeWeese TL: Enhanced radiation and chemotherapy-mediated cell killing of human cancer cells by small inhibitory RNA silencing of DNA repair factors. Cancer Res 2003, 63:1550-1554

38. Foulkes WD: BRCA1 and BRCA2: chemosensitivity, treatment outcomes and prognosis. Fam Cancer 2006, 5:135-142.

39. Ayoub N, Jeyasekharan AD, Bernal JA, Venkitaraman AR: HP1-beta mobilization promotes chromatin changes that initiate the DNA damage response. Nature 2008, 453:682-686.

40. Zhong Q, Chen CF, Li S, Chen Y, Wang CC, Xiao J, Chen PL, Sharp ZD, Lee WH: Association of BRCA1 with the hRad50-hMre11-p95 complex and the DNA damage response. Science 1999, 285:747-750.

41. Honrado E, Osorio A, Palacios J, Milne RL, Sanchez L, Diez O, Cazorla A, Syrjakoski K, Huntsman D, Heikkila P, Lerma E, Kallioniemi A, Rivas C, Foulkes WD, Nevanlinna $H$, Benitez J: Immunohistochemical expression of DNA repair proteins in familial breast cancer differentiate BRCA2associated tumors. J Clin Oncol 2005, 23:7503-7511.

42. Martin RW, Orelli BJ, Yamazoe M, Minn AJ, Takeda S, Bishop DK: RAD51 upregulation bypasses BRCA1 function and is a common feature of BRCA1deficient breast tumors. Cancer Res 2007, 67:9658-9665.

43. Sorlie T, Tibshirani R, Parker J, Hastie T, Marron JS, Nobel A, Deng S, Johnsen H, Pesich R, Geisler S, Demeter J, Perou CM, Lonning PE, Brown PO, Borresen-Dale AL, Botstein D: Repeated observation of breast tumor subtypes in independent gene expression data sets. Proc Natl Acad Sci USA 2003, 100:8418-8423.

44. Turner N, Tutt A, Ashworth A: Hallmarks of 'BRCAness' in sporadic cancers. Nat Rev Cancer 2004, 4:814-819.

45. Carey LA, Dees EC, Sawyer L, Gatti L, Moore DT, Collichio F, Ollila DW, Sartor Cl, Graham ML, Perou CM: The triple negative paradox: primary tumor chemosensitivity of breast cancer subtypes. Clin Cancer Res 2007, 13:2329-2334.

46. Lakhani SR, Vijver Van De MJ, Jacquemier J, Anderson TJ, Osin PP, McGuffog L, Easton DF: The pathology of familial breast cancer: predictive value of immunohistochemical markers estrogen receptor, progesterone receptor, HER-2, and p53 in patients with mutations in BRCA1 and BRCA2. J Clin Oncol 2002, 20:2310-2318.

47. Foulkes WD, Metcalfe K, Sun P, Hanna WM, Lynch HT, Ghadirian P, Tung N, Olopade OI, Weber BL, McLennan J, Olivotto IA, Begin LR, Narod SA: Estrogen receptor status in BRCA1- and BRCA2-related breast cancer: the influence of age, grade, and histological type. Clin Cancer Res 2004, 10:2029-2034.

doi:10.1186/bcr2486

Cite this article as: Asakawa et al.: Prediction of breast cancer sensitivity to neoadjuvant chemotherapy based on status of DNA damage repair proteins. Breast Cancer Research 2010 12:R17. 